\title{
Poster Papers
}

